\title{
Imaginación, (per)formatividad, (improvis)acción: filosofía de la imagen, filosofía como imagen en el pensamiento de Fichte
}

\section{Alessandro Bertinetto}

\section{CpenEdition}

\section{Journals}

Edición electrónica

URL: http://journals.openedition.org/ref/1461

DOI: 10.4000/ref.1461

ISSN: 2258-014X

Editor

EuroPhilosophie Editions

Referencia electrónica

Alessandro Bertinetto, «Imaginación, (per)formatividad, (improvis)acción: filosofía de la imagen, filosofía como imagen en el pensamiento de Fichte», Revista de Estud(i)os sobre Fichte [En línea], 201 2020, Publicado el 01 junio 2020, consultado el 26 enero 2021. URL: http://journals.openedition.org/ ref/1461 ; DOI: https://doi.org/10.4000/ref.1461

Este documento fue generado automáticamente el 26 enero 2021.

() EuroPhilosophie 


\title{
Imaginación, (per)formatividad, (improvis)acción: filosofía de la imagen, filosofía como imagen en el pensamiento de Fichte
}

\author{
Alessandro Bertinetto
}

En este artículo intentaré resumir mi punto de vista sobre el pensamiento de Fichte, articulando los aspectos de la filosofía de Fichte que me parecen centrales en mi investigación filosófica actual. Por lo tanto, no voy a elaborar un análisis filológico de los textos fichteanos, ni tampoco voy a desarrollar una investigación exhaustiva de la compleja articulación de la especulación filosófica fichteana ${ }^{1}$; más bien extrapolaré del pensamiento fichteano algunas conexiones conceptuales, sugiriendo algunos temas que me interesan para la elaboración de mi propia perspectiva filosófica. En otras palabras, no seré fiel a la letra de los escrito de Fichte, pero al menos intentaré ser fiel a su espíritu, en la perspectiva del pensar autónomamente y del con-filosofar que Fichte siempre ha requerido de sus alumnos.

En el centro de mi reflexión está el papel al mismo tiempo performativo y autorreflexivo que Fichte atribuye a la imaginación, entendida en un sentido casi etimológico como una fuerza o facultad de figuración, y conectada de manera estructural a la intuición intelectual (noción que en las últimas exposiciones de la Doctrina de la ciencia también tomará el nombre de "intelecto absoluto"). La schaffende Einbildungskraft se entiende como esa actividad de construcción formativa, plástica, de la Wirklichkeit que opera, por así decirlo, detrás de la conciencia y que también es la génesis de la conciencia, que no es más que las imágenes que ella construye (es decir: es la experiencia que ella hace). La intellektuelle Anschauung (intuición intelectual) es esta misma actividad considerada desde el lado de su autoconciencia. Con el primer concepto, el de imaginación, se subraya el carácter figurativo y constructivo; con el segundo, el carácter de autoconciencia activa del yo. En otras palabras, la imaginación es la actividad figurativa y esquemática del yo; la intuición intelectual, por otro lado, expresa la estructura auto-relacionada y 
autoconsciente de la actividad genética del yo, que es una condición de posibilidad de la "ejecución" de la Doctrina de la ciencia como una reflexión sobre el saber o autoreflexión del saber sobre sus propias estructuras y condiciones de posibilidad. Este aspecto ya lo había captado con precisión el filósofo turinés Luigi Pareyson, quien había argumentado a este respecto la tesis del carácter eminentemente estético de la filosofía fichteana ${ }^{2}$. En general, la razón de la ausencia de una estética como disciplina particular de La Doctrina de la ciencia dependería, según Pareyson, del hecho de que la Doctrina de la ciencia tiene una connotación estética en su conjunto, debido al papel crucial que la imaginación productiva desempeña en su marco teórico, y que se puede articular en las siguientes tareas:

1. unificación de lo sensible (fenómeno) e inteligible (noúmeno);

2. mediación entre factualidad y naturaleza genética del saber y del discurso filosófico sobre el saber;

3. condición de auto-comprensión de la misma filosofía.

Fichte entiende el ejercicio de la imaginación como una condición de posibilidad de la experiencia, es decir de la representaciones de la realidad que la conciencia construye inconscientemente, y como una condición de posibilidad de acceso a, y ejercicio de, la Doctrina de la ciencia en tanto que investigación genético-trascendental del saber y de la experiencia. De hecho, precisamente como condición de la posibilidad del saber la imaginación es también una condición de posibilidad de reflexión filosófica sobre el saber $^{3}$.

En la raíz de la filosofía trascendental fichteana está pues la idea de que la filosofía es el resultado de la misma actividad (libre y espontánea) que ella misma entiende como condición de posibilidad de la experiencia y del saber. La comprensión de la Doctrina de la ciencia requiere y presupone un ejercicio de libertad imaginativa, operativa, constructiva, gestáltica, que permite comprender aquellas operaciones que la Doctrina de la ciencia presenta como constitutivas del saber en tanto que operaciones que constituyen la misma Doctrina de la ciencia, que, de hecho, también es saber: saber sobre las modalidades operativas del saber; o sea, imagen autoconsciente y autoformada de la imagen.

Por lo tanto, las facultades que la Doctrina de la ciencia exhibe como condición de posibilidad del saber y de la experiencia no son presentadas por Fichte de manera descriptiva, como lo haría Kant ${ }^{4}$, que no se reflejaría sobre las operaciones filosóficas por él realizadas, sino que se exhiben y deducen genéticamente durante su propio ejercicio. El punto de vista de la Doctrina de la ciencia es estético, en el sentido de que la imaginación se entiende como práctica de acceso al discurso filosófico a través del discurso filosófico mismo. El ejercicio de la imaginación productiva es la condición para la ejecución de la Doctrina de la ciencia. Este es el significado de la tesis, defendida en la Doctrina de la ciencia nova methodo y en el Sistema de Ética de 1798, según el cual el punto de vista estético media entre el punto de vista empírico y el punto de vista trascendental ${ }^{5}$.

El punto de vista estético, en la perspectiva de una estética predominantemente orientada a la producción, actúa como intermediario hacia el punto de vista trascendental. De hecho, el punto de vista estético permite levantarse sobre la conciencia empírica en virtud de la comprensión de su fuerza plástica, es decir, de la 
comprensión de la actividad creativa de ese Bilden cuyo ejercicio es la presuposición del éxito de la Doctrina de la ciencia en tanto que práctica de reflexión sobre el Bilden como condición de la conciencia. La imaginación productiva se produce y se capta a sí misma, al igual que la intuición intelectual que es su modalidad cognitiva.

Se podría decir entonces que el problema crucial en la raíz del pensamiento fichteano es cómo hacer coherente la doctrina kantiana del esquematismo trascendental que Kant presentaría de una manera aún factual. La crítica de Fichte a Kant es fundamentalmente la siguiente: en el estudio de las estructuras del yo (de la conciencia, del espíritu) Kant pierde precisamente lo específicamente propio del yo, es decir su carácter de actividad. Kant describe objetivamente las estructuras del yo, sin reflexionar sobre esta operación objetivadora. No se da cuenta de que la filosofía trascendental es la reflexión sobre la actividad del espíritu humano (es decir, de la conciencia); pero esta reflexión coincide con la actividad del espíritu humano. Por lo tanto, Kant objetiva la conciencia, que es actividad (Bilden), convirtiéndola en un objeto representado y, de esta manera, pierde precisamente lo que debería clarificar filosóficamente, a saber, el yo en tanto que actividad.

En cambio, Fichte pretende resaltar precisamente esto: la reflexión sobre el espíritu ya es la actividad del espíritu; y el espíritu debe captarse a sí mismo precisamente en esta operación: en, y en tanto que, actividad. La reflexión filosófica es la misma actividad del espíritu que reflexiona sobre sus propias estructuras reflexivas. Por lo tanto, esta misma reflexión solo puede tomar una forma circular y recursiva. Las leyes del espíritu, que la Doctrina de la ciencia debe investigar, son de hecho las mismas leyes que debe implementar en su investigación. El problema subyacente a la filosofía trascendental es, entonces, el círculo en el que debe moverse su pensamiento que debe presuponer aquella libertad genética que precisamente debe argumentar.

Coherentemente con esto, la estructura de la Doctrina de la ciencia es circular. Su iniciación objetiva recibe justificación genética solo de la serie de deducciones a las que realmente se ha iniciado. Esta estructura corresponde a la naturaleza espiritual de la filosofía como acto genético y ocurre en todas las exposiciones de la Doctrina de la ciencia. Ahora, la circularidad de la estructura argumentativa de la Doctrina de la ciencia se debe al hecho de que la filosofía no es más que el ejercicio de la imaginación productiva, del espíritu, que investiga genéticamente la imaginación productiva: la Doctrina de la ciencia es la aplicación de la intuición intelectual a sí misma. Por lo tanto, la filosofía no puede reducirse a mera letra. No puede ser objetivada, porque cada objetivación, cada aprehensión mnemónica y mecánica de la reflexión performativa sobre el saber la solidifica en un aparato de fórmulas en el que se pierde el auténtico sentido filosófico.

El horizonte conceptual en el que se inscribe la versión fichteana del trascendentalismo es el de una concepción constructivista, es decir, performativa de la experiencia y la reflexión. La filosofía se pone y ex-pone a sí misma como un "sistema de la libertad", como Fichte escribió en una carta a su amigo Baggesen en $1795^{6}$ : un "sistema de la libertad" que no va más allá de los límites del conocimiento crítico, sino que legitima la posición de estos mismos límites a través de la comprensión reflexiva del hecho de que tan solo la génesis del plano de la inmanencia trasciende, si así se puede decir, el plano de la inmanencia: en otras palabras, lo que transciende el plano de la imagen en tanto que resultado de la performance del figurar (o imaginar) como actividad del espíritu (o espíritu como actividad) y de la reflexión sobre ello es solo libre o absoluta 
performatividad, es decir es solo la implementación de la "fuerza de figuración" que hay que presuponer para comenzar la reflexión filosófica.

En la expresión "sistema de libertad", el genitivo es tanto objetivo como subjetivo. Por un lado, la Doctrina de la Ciencia es exposición de las condiciones de libertad, del yo (o saber) en tanto que actividad, figuración de la realidad y condición de la experiencias, y en tanto acto que hay que ejecutar - en libre respuesta de una invitación por parte del filósofo (como bien enseña especialmente la Doctrina de la ciencia nova methodo ${ }^{7}$ ). Por otro lado, y coherentemente, la libertad es, por así decirlo, el agente de la Doctrina de la ciencia misma. Así, la exposición (Darstellung) del saber no solo presenta las condiciones del saber de manera objetiva; más bien, la exposición del saber es la ejecución en acto del saber sobre la libertad: es decir, es performance de la libertad misma: auto-realización de la libertad y auto-exhibición de la libertad en esta autorealización.

En otras palabras: la exposición del saber sobre la libertad en tanto que esencia del yo o del saber es ejercicio de libertad. Por lo tanto, Fichte inserta la primacía de lo práctico en el corazón mismo de la investigación teórica sobre las condiciones del saber. Pero, como dije al comienzo de estas reflexiones, Fichte le da a esta primacía una curvatura estética, ya que la clave para comprender la implicación del principio incondicional del saber (es decir: la libertad) (que presenta las condiciones del saber) en la exposición del saber mismo es la imaginación productiva.

A este respecto, se puede decir que Fichte convierte el juicio reflexionante, que para el Kant de la Kritik der Urteilskraft tenía tan sólo una validez regulativa y subjetiva, en raíz trascendental, al mismo tiempo ontológica y gnoseológica, de la filosofía. Para Kant, el único juicio objetivamente válido a nivel cognitivo es el juicio determinante. En consecuencia, la imaginación (Einbildungskraft) es por cierto entendida como una "facultad productiva del saber", que produce libremente "ideas estéticas"; sin embargo dicha producción no establece experiencia ni saber, porque las ideas estéticas son intuiciones que no son adecuadas a conceptos y por esta razón permanecen indeterminadas. La función simbólica y metafórica del uso reflexivo y no determinante de la imaginación se opone entonces a la función de esquematización, y su resultado es la construcción de analogías más bien que el establecimiento de significados. Si en este caso se puede hablar de esquematismo, se trata, como propuso Paul Ricoeur, de un "esquematismo sin concepto". Por lo tanto, en Kant faltaría la conexión entre la explicación de las posibilidades formativas y creativas del juicio y de la imaginación y la determinación semántica de los conceptos: es decir, en Kant falta la conexión entre el principio productivo de la conciencia y del saber, así como de la misma auto-reflexión filosófica, y la explicación de las condiciones de la conciencia y de la experiencia como manifestación, y condiciones factuales, del principio, a saber, la libertad productiva de la imaginación (o dicho de otra manera la imaginación como libertad productiva). Fichte, por otro lado, extiende explícitamente el potencial creativo de la imaginación, es decir, la imagen como una fuerza de formación / figuración, Kraft des Bildens ${ }^{10}$, a la misma actividad cognitiva, o más bien poiético-cognitiva. Una vez que el concepto de "cosa en sí" ha sido firmemente rechazado como contradictorio, el saber no es comprendido entonces como representación o reflejo de "cosas en sí", sino como la imagen y fenómeno de lo absoluto, es decir de la libertad o de la génesis (que aparece en el saber) y, por lo tanto, como formación y construcción plástica de la Wirklichkeit (a través de conceptos que organizan la experiencia) y del mundo ético (a través de la producción de visiones ideales imaginativas - Gesichter ${ }^{11}$ - que dan forma a la realidad). 
En este sentido, el esquema-imagen es Vorbild (modelo, prefiguración), en lugar de Nachbild (copia, representación). La doctrina del esquematismo se funda pues como un desarrollo coherente de la doctrina de la imagen a nivel de comprensión de la génesis de la experiencia, que, auto-reflexivamente y recursivamente, es al mismo tiempo la comprensión genética de las modalidades de comprensión de la génesis de la experiencia. A través de esta asimilación reflexiva de la actividad esquematizadora, Fichte corrige el carácter subjetivista que domina la problemática kantiana de la imaginación, porque no solo el objeto, sino también la conciencia se entiende como un producto de la actividad esquematizadora del figurar (Bilden) de la libertad (o vida, o génesis, o actividad pura, o absoluto). En resumen, el esquematismo no solo se afirma como ese "arte oculto" por el cual la conciencia estructura el mundo que experimenta; más bien es conscientemente performado por la Doctrina de la ciencia en tanto que "esquematismo del esquematismo" ${ }^{12}$.

En este sentido, como explicación de la estructura auto-reflexiva y recursiva, así como plástica y productiva, del saber, la "doctrina de la imagen" que Fichte elabora después de 1800 es un desarrollo coherente de la teoría de la autoconciencia elaborada en las exposiciones de la Doctrina de la Ciencia de los años de Jena. No se trata de teorías diferentes, sino de diferentes niveles de profundidad reflexiva de una sola visión filosófica. La conceptualidad operacional en la teoría de la imagen nos permite exponer efectivamente el núcleo argumentativo de la Doctrina de la ciencia en tanto que una teoría del saber genético-trascendental. Si en los años de Jena (1793-99) esta teoría se articuló en torno al concepto del yo como Tathandlung e "intuición intelectual", y en la fase media en torno a la relación entre Factum y Génesis, en la Spätphilosophie berlinesa, estos conceptos se reubican dentro de la Doctrina de la ciencia como Bildtheorie. El núcleo conceptual, sin embargo, no cambia. Lo que pasa, es más bien que el vínculo estructural entre el objeto de la reflexión de la Doctrina de la ciencia (las estructuras de conciencia y del saber) y la misma operación en la que consiste la Doctrina de la ciencia ahora se profundiza. En la reconstrucción genética de la conciencia como imagen, la Doctrina de la ciencia se justifica reflexiva y recursivamente, se presenta como imagen y, por lo tanto, exhibe específicamente su participación en la relación entre imagen y absoluto (saber/libertad, consciencia/ génesis o Tathandlung) que constituye la imagen como dimensión ontológicoepistemológica del saber y de la conciencia.

Pero el aspecto fundamental del paso que Fichte hace más allá de Kant es el siguiente: la estructura recursiva del juicio reflexionante que opera produciendo imaginativamente una regla a partir del caso único o, paradójicamente, generando una regla gracias a su aplicación, es decir operando de manera abductiva (como habría dicho Peirce ${ }^{13}$ ), se inserta en el corazón de la lógica trascendental que constituye el marco argumentativo de la Doctrina de la ciencia. La Doctrina de la ciencia se enfrenta a la tarea, imposible de satisfacer sobre la base de una lógica formal basada en el juicio determinante y en el principio de razón suficiente, de fundar el saber como una imagen de la libertad (o dicho de otro modo: fenómeno de lo absoluto, o vida) mientras se pone y se refleja a sí misma en tanto que imagen de la libertad. De esta manera, debe entender la imagen como una operación, y no simplemente como una estructura, performativa y autorreflexiva de reduplicación entre sí misma y el otro (el ser), o sea, como articulación interna a la libertad (o al absoluto, o a la génesis): como manifestación de la libertad que es ya libertad. 
Es aquí donde entendemos cómo el destino de la Doctrina de la ciencia, como una exposición de las estructuras del saber (de la conciencia, del ego) en tanto que manifestación (o fenómeno) del principio absoluto (la libertad) que es asumido como condición de posibilidad para el ejercicio de la Doctrina de la ciencia misma, es el del depositarse, o quitarse o substraerse como reflexión meramente teórica y convertirse en sabiduría práctica, o práctica de libertad - libertad de actuar creativamente de la imaginación.

La centralidad teórica de la estructura performativa del juicio reflexionante permite estructurar la exposición del saber como un "sistema abierto" de tipo luhmaniano. Según Luhmann ${ }^{14}$, quien adopta la idea de autopoiesis de Maturana y Varela ${ }^{15}$, un sistema abierto es tal que los resultados del proceso que lo constituyen vuelven a entrar recursivamente en el proceso como sus condiciones. Fichte anticipa esta figura conceptual ya que produce un pensamiento que se expone articulándose recursivamente en tanto que manifestación de un principio asumido que debe de ser demostrado y que, para ser demostrado, requiere la auto-reflexión del saber como imagen del principio que aparece solo en la imagen como actividad gestáltica, es decir, requiere la auto-destrucción del saber mismo como imagen o representación meramente objetiva. El saber filosófico es tal si cumple su propia aniquilación como mera imagen (o mero saber representacional) y expresa la libertad actuándola en y como Bilden práctico.

Aquí también radica la idea que quiero sugerir al final de este artículo: la tesis que la filosofía de la acción o la filosofía de la práctica que es el resultado de la Doctrina de la ciencia como una doctrina de la imagen que es imagen (y se sabe a ella misma como imagen) y como tal se resta para manifestar el principio productivo de la imagen (la libertad) en tanto que fuerza de la imagen, esta filosofía de la acción es, más bien, una filosofía de la improvisa acción: filosofía de la improvisación.

De hecho, por un lado, la improvisación también es estructurada como un sistema abierto en el que los resultados del proceso se convierten en condiciones del proceso y cuya normatividad se articula en el curso del proceso mismo en función de la situación concreta de su emergencia. Así, la estructura del proceso de la improvisación es la misma que la del juicio reflexionante que genera su propia normatividad a partir del caso individual específico. La improvisación es "enactment of the aesthetic judgment", come ha recientemente escrito Gary Peters en referencia a Kant ${ }^{16}$.

Por otro lado, de hecho, las formas factuales concretas en que se realiza la acción improvisada no pueden deducirse de normas preestablecidas, porque las normas se generan precisamente gracias a la acción misma en situaciones concretas. Lo cual corresponde perfectamente a la idea de Fichte de que la estructura trascendental del saber como sistema de la libertad o sistema abierto es una e inmutable, mientras que sus exposiciones y, sobre todo, las formas en que la Doctrina de la ciencia actúa concretamente la libertad, eliminandose a sí misma como (exposición del) saber, no son deducibles, sino que varían con la variación impredecible de la situación histórica concreta.

Hannah Arendt, en su interpretación política de las ideas kantianas sobre el juicio reflexionante, había aplicado la normatividad performativa que Kant atribuye a la acción reflexiva, a la acción auténticamente creadora, afirmando que la acción humana es realmente tal - y no mera fabricación - si es iniciativa, comienzo, es decir, si produce lo nuevo. En otras palabras, la acción humana es realmente tal si es libre, o si produce 
su normatividad, es decir, si es improvisación: la articulación performativa de la imaginación ${ }^{17}$.

Creo que uno de los resultados filosóficos más significativos del pensamiento de Fichte es haber injertado esta creatividad de tipo improvisacional en el corazón mismo del riguroso autoconocimiento del saber operado por la Doctrina de la ciencia, teorizando la libertad imaginativa al mismo tiempo en tanto que presuposición ontológica y como consecuencia práctica de la reflexión filosófica sobre el saber y de la concomitante auto-reflexión de la filosofía como saber del saber, imagen de la imagen, es decir, como Doctrina de la ciencia.

En conclusión, se puede decir que el espíritu del pensamiento de Fichte vive en esas prácticas (considerando como práctica también el pensamiento, como es obvio, por supuesto) que no se limitan a imitar de manera literal a un modelo, y, al revés, buscan su camino de manera inventiva, comenzando algo nuevo, articulando su propia normatividad y exponiéndose como una manifestación de libertad: libertad que se realiza, como principio del saber y de la Wirklichkeit, solo en su concreto, e impredecible, ejercicio.

\section{BIBLIOGRAFÍA}

ARENDT, H., (1958) The Human Condition. Chicago: Chicago University Press. ARENDT, H., (2003) Responsibility and Judgment. New York: Schocken Books. ASMUTH, CH., (2009) Kant und Fichte - Fichte und Kant, FICHTE-STUDIEN 33. BERTINETTO, A., (2001), L'essenza dell'empiria. Saggio sulla prima "Logica trascendentale" di J. G. Fichte. Napoli: Loffredo.

BERTINETTO, A., (2010) La forza dell'immagine. Argomentazione trascendentale e ricorsività nella filosofia di J.G. Fichte. Milano: Mimesis.

BERTINETTO, A. (2014) "Die absolute Kraft des Bildens". Image et conscience de soi dans la Doctrine de la Science de Fichte, FICHTE-STUDIEN, 41, 45-71.

BERTINETTO, A., MARINO, S. (forthcoming) "Kant's Concept of Power of Judgment and the Logic of Artistic Improvisation" en: MARINO, S., TERZI, P. (eds.) Kant's Critique of Aesthetic Judgment in the Twentieth Century. Berlin: De Gruyter.

KANT, I., (1790) Kritik der Urteilskraft, Ak. Aus. V (1908), 165-485.

LUHMANN, N. (1984), Soziale Systeme. Frankfurt a.M.: Suhrkamp.

MATURANA, H., VARELA, F. (1980), Autopoiesis and Cognition: The Realization of the Living. Boston: Reidel Pu \& Co.

PAREYSON, L., (1976) Fichte. Il sistema della libertà. Milano: Mursia.

PEIRCE, C. S., (1931) Collected Papers, Vol. V, Cambridge MA: Harvard University Press. RAMETTA, G., (2002) “L'idea di filosofia nel tardo Fichte”, RIVISTA DI STORIA DELLA FILOSOFIA, 461-468.

RAMPAZZO BAZZAN, M. (2008) "La nozione di Gesicht nel tardo Fichte”. en: PANNO, G. (ed.) Il silenzio degli angeli. Padova: Unipress, 79-95.

PETERS, G., (2017) Improvising improvisation. From out of philosophy, music, dance, and literature. The University of Chicago Press: Chicago and London.

RICOEUR, P., (2002) Cinque lezioni. Dal linguaggio all'immagine. Palermo: Aesthetica Preprint. 


\section{NOTAS}

1. Para este tipo de trabajo remito a Bertinetto 2001 y Bertinetto 2010.

2. Pareyson 1976: 118.

3. Véase GWL, GA I/2, 415.

4. Por lo menos según la interpretación fichteana de Kant. Al respecto véase Asmuth (ed.) 2009.

5. SSL, GA I/5, 307-308; WLnm-k, GA IV 3, 522.

6. GA III/2, 298.

7. Wlnm-h, GA IV/2, 263; Wlnm-k, GA IV/3, 520.

8. Kant 1990, XXVI-XXVII, 63, 69, 193.

9. Ricoeur 2002, 48.

10. WL 1813, GA II/15, 135.

11. Sobre este concepto véase Rametta 2002 y Rampazzo Bazzan 2008.

12. WL 1813, GA II/15, 163 ss. Véase Bertinetto 2014.

13. Peirce 1931, 172.

14. Luhmann 1984.

15. Maturana, Varela 1980.

16. Peters 2017, 40. Véase Bertinetto, Marino forthcoming.

17. Arendt 1958; Arendt 2003.

\section{RESÚMENES}

Articulando los aspectos de la filosofía de Fichte que me parecen centrales en mi investigación filosófica actual, en este artículo defenderé que uno de los resultados filosóficos más significativos del pensamiento de Fichte es haber injertado una creatividad de tipo improvisacional en el corazón mismo del riguroso autoconocimiento del saber operado por la Doctrina de la ciencia. Este posicionamiento, teoriza la libertad imaginativa al mismo tiempo como que presuposición ontológica. El resultado es una consecuencia práctica de la reflexión filosófica sobre el saber y de la concomitante auto-reflexión de la filosofía como saber del saber, imagen de la imagen, es decir, como Doctrina de la ciencia.

\section{ÍNDICE}

Keywords: imaginación, improvisación, libertad, auto-reflexión, juicio reflexionante

\section{AUTOR}

\section{ALESSANDRO BERTINETTO}

University of Turin/ART - Aesthetics Research Torino 